\title{
Executive Insights: \\ Integrating Branding Strategy Across Markets: \\ Building International Brand Architecture
}

Brands play a critical role in establishing a firm's visibility and position in international markets. Building a coherent international brand architecture is a key component of the firm's overall international marketing strategy, because it provides a structure to leverage strong brands into other markets, assimilate acquired brands, and integrate strategy across markets. The authors examine the way firms have developed international brand architecture and the drivers that shape the architecture. The authors discuss implications for the design and management of the firm's international brand architecture.

With the globalization of markets and the growth of competition on a global scale, companies are increasingly expanding the geographic scope of their operations, acquiring companies in other countries, and entering into alliances across national boundaries. At the same time, with the spread of global and regional media, the development of international retailing, and the movement of people, goods, and organizations across national borders, markets are becoming more integrated. As a result, firms need to pay greater attention to coordinating and integrating marketing strategy across markets.

An important element of a firm's overall marketing strategy is its branding policy. Strong brands help the firm establish an identity in the marketplace and develop a solid customer franchise (Aaker 1996; Kapferer 1997; Keller 1998), as well as provide a weapon to counter growing retailer power (Barwise and Robertson 1992). They can also provide the basis for brand extensions, which further strengthen the firm's position and enhance value (Aaker and Keller 1990). In international markets, the firm's branding strategy plays an important role in integrating the firm's activities worldwide. A firm can, for example, develop global brands (using the same brand name for a product or service worldwide) or endorse local country brands with the corporate brand or logo, thus establishing a common image and identity across country markets.

Typically, the firm's international branding strategy is formed through an evolutionary process that results from decisions to enter new country markets or expand product offerings within an existing country. Often firms make these decisions piecemeal on a country-by-country, product division, or product

\author{
ABSTRACT
}

\section{Susan P. Douglas, C. Samuel Craig, and Edwin J. Nijssen}

Submitted August 1999 Revised February 2001

() Journal of International Marketing Vol. 9, No. 2, 2001, pp. 97-114 ISSN 1069-031X 
line basis, without considering the overall balance or coherence of branding in international markets from a strategic perspective. However, as international markets evolve and become more closely interlinked, firms need to pay closer attention to the coherence of branding decisions across national markets and build an effective international brand strategy that transcends national boundaries (Caller 1996). In addition, the firm must decide how to manage brands that span different geographic markets and product lines. It must determine who should have custody of international brands and who is responsible for coordinating their positioning in different national or regional markets, as well as making decisions about use of a given brand name on other products or services.

As a first step, the firm must examine its branding strategy and formulate the basic principles to guide the effective use of brands in the global marketplace. These principles must also establish a rationale for harmonizing branding decisions at different levels of the organization and across different geographic locations. These decisions should provide strategic direction and indicate which brands should be emphasized at what levels in the organization, how brands are used and extended across product lines and countries, and the extent of brand coordination across national boundaries. This process and outcome can be termed the firm's international brand architecture. Just as architectural plans provide the basis for a sound building, international brand architecture establishes the plan for developing a sound branding strategy.

The purpose of this article is to examine the issues involved in building this architecture. We examine current perspectives on international branding. This is followed by a discussion of the underlying drivers of brand structures, that is, firm characteristics, product-market structure and market dynamics, and emerging patterns in international markets. We next discuss the importance of designing a clear and effective brand architecture and managing brands in order to maintain a harmonious balance within this architecture. We conclude by emphasizing the need for an annual audit of the firm's brand architecture and its fit with changes in the underlying drivers as well as an assessment of key strategic brands within this architecture.

Most discussion and research on branding, whether domestic or international, focuses on the equity or value associated with a brand name and the factors that create or are the underlying source of value (Aaker 1996; Keller 1998). Although this focus is appropriate for relatively few high-profile brands, such as Nike, Marlboro, or McDonald's, it ignores the challenges faced by the vast majority of multinational firms that own a variety of local and international brands at different levels in the organization, spanning a broad range of diverse country markets. Typically, these brands differ in their 
strength, target market, and associations and the range of products covered both within and across markets. Equally, the use of brands at different organizational levels may vary from country to country.

The questions faced by the firm in developing an international branding strategy depend on how it has expanded internationally and how its international operations are organized. Some firms, such as Procter \& Gamble (P\&G) and Coca-Cola, have expanded through leveraging their domestic "power" brands in international markets. Consequently, as they seek to expand further, they must consider whether to develop brands geared to specific regional or national preferences and how to integrate these into their brand strategy. Other firms such as Nestlé and Unilever have traditionally adopted country-centered strategies, building or acquiring a mix of national and international brands. Such companies must decide how far to move toward greater harmonization of brands across countries and how to do so. Such issues are particularly salient in markets outside the United States, where the concept of "power" branding is relatively new (Court et al. 1997). Markets are often fragmented and characterized by small-scale distribution and often lack the potential or size to warrant the use of heavy mass media advertising that is needed to develop strong brands (Barwise and Robertson 1992).

Relatively little attention has been paid to the question of brand structure or brand architecture. Here, brand structure is used to refer to the firm's current set of brands across countries, businesses, and product-markets. At any given point, brand structure is in large measure a legacy of past management decisions as well as the competitive realities the brand faces in the marketplace. Brand architecture, in contrast, refers to a formal process and outcome by which management rationalizes the firm's brands and makes explicit how brand names at each level in the organization will be applied. Brand architecture also indicates how new brands, whether acquired or developed internally, will be treated.

Some authors (Laforêt and Saunders 1994; Olins 1989) have developed frameworks of branding structure or brand architecture in relation to a single national market. Typically, these focus on identifying different levels related to the brand name and/or visual associations of the brand. Olins (1989), for example, has identified three branding structures: monolithic (a corporation uses one name and identity worldwide, e.g., Kellogg or Shell), endorsed (the corporate name is used in association with a subsidiary or product brand, e.g., Cadbury's Dairy Milk), and branded (emphasizes multiple product-level brands, e.g., P\&G using brands such as Tide and Camay). 
Laforêt and Saunders (1994) examine the structure of brands among a sample of 20 grocery manufacturers in the United Kingdom and conclude that brand structures are inherently more complex than Olins proposes. They identify three principal categories similar to those identified by Olins: corporate brands, mixed brands, and brand dominant. Each of these categories includes subcategories. The corporate-dominant group is divided into corporate brands, for which the corporate name was used, and house brands, for which the subsidiary or product division names were used, such as Ford with Jaguar. Mixed brands include endorsed brands (a product-level brand is endorsed by a corporate name), such as Rowntree's Chocolite, and dual brands, for which two or more brands are given equal prominence, such as ColgatePalmolive or Cadbury's Dairy Milk. The third category, brand-dominant, consists of single product-level brands such as Ariel (P\&G) Tabasco sauce (SmithKline Beecham) and furtive brands, for which the corporate identity is omitted. For example, Unilever identifies its detergent brands as made by Lever Bros. and its margarine as van den Bergh. Not only is the structure considerably more complex than commonly assumed, but also most companies studied used more than one approach, often adopting different options for different product lines or businesses.

As the firm expands in international markets, issues related to brand architecture or brand structure become even more complex. In addition to determining the position and role of each brand in the firm's architecture, management also must make decisions related to another dimension, namely, its geographic scope. Issues of brand coordination and consistency of brand positioning across countries also must be resolved. Especially if the company expands through acquisition or strategic alliances, the question of whether and how the brands of different firms are merged arises.

In essence, a firm's international brand structure is fashioned by three major factors: firm-based characteristics, productmarket characteristics, and underlying market dynamics (see Figure 1). The firm's history shapes its current brand strategy, but market dynamics and the growth of economic and political integration as well as rising media costs create pressures to harmonize branding across country-markets to achieve economies of scale and scope. As a result, brand structure, similar to a living organism, is continually changing, both shaped by and evolving in response to these drivers. ${ }^{1}$

Brand structure inevitably reflects the imprimatur of previous generations of management directives. In the first place, the firm's administrative heritage-and in particular its organizational structure-establishes the template for its brand architecture. Also, the firm's international expansion strategy 


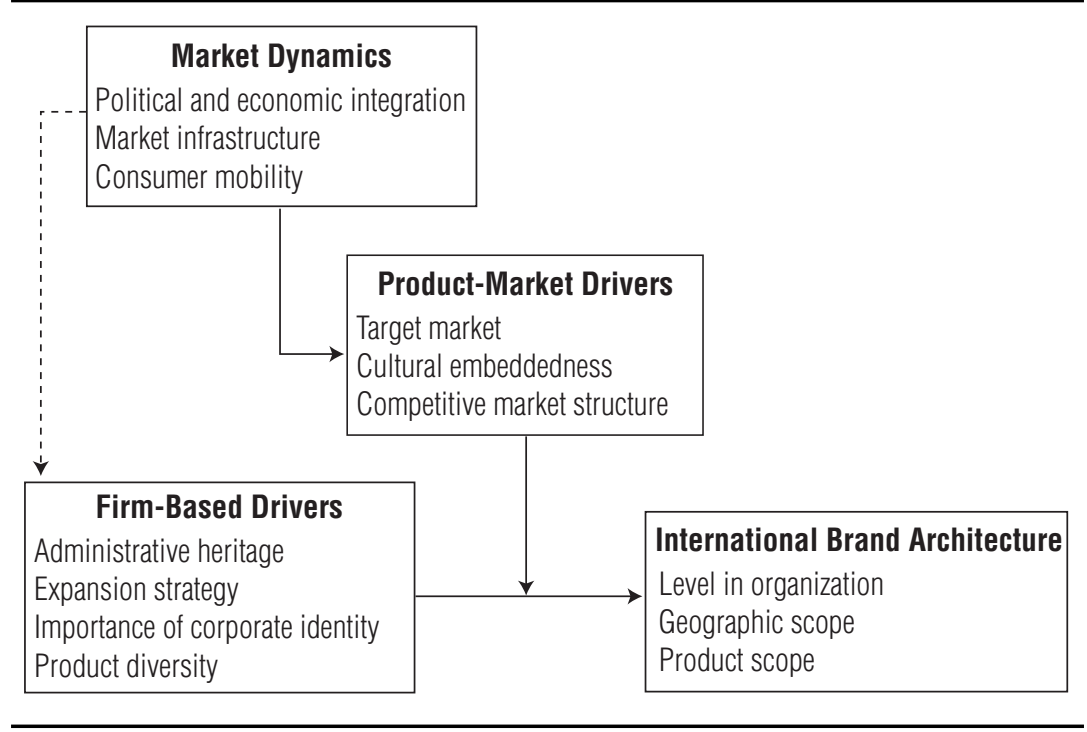

and notably the mode of expansion, through acquisition or organic growth, affect how brand structure evolves over time. Entry into strategic alliances to broaden the geographic scope of the firm's operations results in a need to meld the branding strategies of the partners. The importance of corporate identity and the diversity of the firm's product lines and product divisions also affect the range and number of brands.

Administrative Heritage. The firm's administrative heritage is central to understanding its branding strategy (Bartlett and Ghoshal 1989). A firm that historically has operated on a highly decentralized basis in which country managers have substantial autonomy and control over strategy as well as day-to-day operations is likely to have a substantial number of local brands. In some cases, the same product may be sold under different brand names in different countries-for example, Unilever's yellow fat brands, Promise and Flora. In other cases, a product may be sold under the same brand name but have a different positioning or formulation in certain countries, such as Häagen-Dazs.

Firms with a centralized organizational structure and global product divisions, such as Sony or Siemens, are more likely to have global brands. Both Siemens and Sony adopt a corporate branding strategy that emphasizes the quality and reliability of their products. Product lines are typically standardized worldwide, with minor variations in styling and features for local country markets.

Expansion Strategy. Closely related to the firm's administrative heritage is its international expansion strategy. Of particular importance in determining the number and composition of the brands owned by the firm is its mode of expansion, that is, whether it has expanded internally or through acquisitions and strategic alliances.
Figure 1.

Framework for Analyzing International Brand Architecture 
Firms that expand internationally by acquiring local companies, even when the primary goal is to gain access to distribution channels, often acquire local brands. If these brands have high local recognition or a strong customer or distributor franchise, the company will normally retain the brand. This is particularly likely if the brand does not occupy a similar positioning to that of another brand currently owned by the firm. Best Foods (recently acquired by Unilever) typically expanded internationally through acquisitions such as Pfanni (a German company selling mashed potatoes and dumplings), Telna (a soup company in Israel), and a sauce company in Chile. These companies were then used as platforms to distribute Best's other brands.

Sometimes a company expands by acquiring companies in the same or related product businesses. For example, when Kimberley-Clark acquired Scott Paper, it also acquired several paper product companies in Europe, some of which had strong local brands. Kimberley-Clark decided to adopt a transition strategy, gradually changing local brands to the Kleenex brand. For example, Kimberley-Clark acquired Page, the leading Dutch brand of tissues, toilet paper, and paper towels, and placed the Kleenex brand on all Page products. The Kleenex name and little dog logo was also used in all promotional campaigns. Over time it is expected that the local brand will become smaller and possibly be phased out.

Other companies have expanded and diversified at the same time through a strategy of acquisition. Nestlé, for example, has expanded by acquiring companies in a range of different product-markets, mostly food and beverage. These range from well-known global brands in mineral water such as Perrier and San Pellegrino and confectionery companies such as Rowntree and Perugina to pet food companies and brands such as Spillers and Alpo and grocery companies such as Buitoni, Crosse \& Blackwell, and Herta. The proliferation of brands obtained through this acquisition from 1960 to 1990 generated a need to consolidate and integrate company branding structures. As a result, an explicit international brand architecture was established.

Firms that have expanded predominantly by extending strong domestic brands into international markets often have a product-level brand strategy. For example, P\&G has rolled out several of its personal products brands, such as Camay and Pampers, into international markets. This strategy appears most effective when customer interests and desired product attributes are similar worldwide and brand image is an important cue for the consumer.

Importance of Corporate Identity. The relative importance placed by the firm on its corporate identity also influences 
brand structure. Companies such as IBM and Apple place considerable emphasis on corporate identity (Schmitt and Simenson 1997). In the case of IBM, "Big Blue" is associated with a solid corporate reputation and reflects the company's desire to project an image of a large reliable computer company that provides products and services worldwide. The IBM logo is featured on products and advertising worldwide to convey this image. Equally, Apple used its colored apple logo to project the image of a vibrant challenger in the personal computer market.

Japanese companies also frequently emphasize corporate identity as a means of reassuring customers and distributors that the company is reliable and stands behind its products. As a result, even companies with highly diverse product lines-such as Kao with detergents, personal care products, and computer floppy disks and records-rely on the corporate brand name (and its logo) to project an image of reliability.

Product Diversity. Another issue is the diversity or conversely the interrelatedness of the product businesses in which the firm is involved. Firms that are involved in closely related product lines or businesses that share a common technology or rely on similar core competencies often emphasize corporate brands. General Electric, for example, is involved in a range of product businesses worldwide from aerospace products and electric generators to medical equipment. All rely heavily on engineering skills. The use of the General Electric name provides reassurance and reinforces the firm's reputation for engineering competency and reliable products worldwide.

Conversely, when firms are involved in a range of diverse product businesses that target different customer segments and have different associations, they sometimes opt to develop separate identities and associations for individual product businesses or products. For example, Unilever has no corporate brand and emphasizes either product or house brands, thus establishing separate identities for its businesses such as food, personal care products, and detergents. It was considered particularly desirable to avoid association between the (now sold) chemicals business and food products. Similarly, P\&G has emphasized product brands in its detergents business to target distinct market segments and avoid creating an impression of market dominance.

Three product-market factors play an important role in brand architecture: the nature and scope of the target market, the cultural embeddedness of the product, and competitive market structure.

Target Market. When the firm targets a global market segment with relatively homogeneous needs and interests worldwide, 
global brands provide an effective means of establishing a distinctive global identity. Luxury brands such as Godiva, Moet and Chandon, Louis Vuitton, and Aveda as well as brands such as Body Shop, Benneton, and L'Oreal's Maybelline are all targeted to the same market segment worldwide and benefit from the cachet provided by their appeal to a global consumer group. Firms may also segment international markets by region, targeting regional segments with similar interests and purchase behavior, such as Euro-consumers. This provides cost efficiencies when such segments are readily accessible through targeted regional media and distribution channels.

Cultural Embeddedness. A critical factor influencing brand structure is the degree of cultural embeddedness of a product. This can be defined as the extent to which there are strong and deeply ingrained local preferences for specific products or product variants (e.g., food) or the products are an integral part of a culture (e.g., national sports, pastimes, cultural rites, icons). As noted previously, markets in which demand is relatively homogeneous worldwide are likely to be prime candidates for global branding at either the corporate or the product level. Conversely, products that are deeply culturally embedded-such as food or, in some cases, household products-are more likely to thrive as local brands. In some cases, they may be products that cater to specific local tastes, such as food products. Particularly, where these are traditional products and market tastes have evolved little over time, a well-established local brand name may have substantial value. In some cases, where the product is associated with local cultural habits and tastes, the use of a local-sounding brand name may be preferable.

Competitive Market Structure. Another factor affecting the firm's branding strategy is competitive market structure. This can be defined as the relative strength of local (national) versus global competitors in a given product-market (Douglas and Craig 1996). If markets are fully integrated and the same competitors compete in these markets worldwide, as in aerospace, the use of global brands helps provide competitive differentiation on a global basis. If strong local, national, or regional competitors as well as global competitors are present in a given national or regional market, the use of a multitier branding structure, including global corporate or product brands as well as local brands, is desirable. Coca-Cola, for example, has not only its global brand of colas but also several local and regional brands that cater to specific market tastes. In Turkey, Coca-Cola has introduced a pear-flavored drink and in Germany a berryflavored version of Fanta (Echikson and Foust 2000).

While the firm's history and the product-markets in which it operates shape the firm's brand structure, market drivers create and continually change the context in which this evolves. 
Political and Economic Integration. Increasing political and economic integration in many parts of the world has been a key factor stimulating the growth of international branding. As governments remove tariff and nontariff barriers to business transactions and trade with other countries and as people and information move easily across borders, the climate has become more favorable to the marketing of international brands. Firms no longer need to modify products to meet local requirements and develop specific variants for local markets but instead can market standardized products with the same brand name in multiple country markets. In many cases, harmonization of product regulation across borders has further facilitated this trend.

Market Infrastructure. The growth of a global market infrastructure has acted as a major catalyst to the spread of international brands. Global and regional media provide an economical and effective vehicle for advertising international brands, particularly when these brands are targeted to focused global and regional market segments, for example, upscale and more affluent consumers, teenagers, and so forth (de Mooij 1997). At the same time, global media play an active role in laying the groundwork for consumer acceptance of and interest in international brands by developing awareness of these brands and the lifestyles with which they are associated in other countries. In many cases, this stimulates a desire for the brands consumers perceive as symbolic of a coveted lifestyle.

The internationalization of retailing has further facilitated and stimulated the development of international manufacturer brands. As retailers move across international borders, they provide an effective channel for international brands, but at the same time their power increases. Consequently, manufacturers need to develop strong brands with high market share in multiple countries to obtain adequate retail space for these brands and minimize slotting allowances (Barwise and Robertson 1992). Strong international brands can also be extended to provide manufacturers with an effective negotiating tool and ensure the placement of new products.

Consumer Mobility. A final factor underlying the power of international brands is increased consumer mobility. While global media provide passive exposure to brands, increasing international travel and movement of customers across national boundaries provides active exposure to brands in different countries (Alden, Steenkamp, and Batra 1999). Awareness of the availability and high visibility of an international brand in multiple countries enhances its value to consumers and provides reassurance of its strength and reliability. Increased exposure to and familiarity with new and diverse products and the lifestyles and cultures in which they are embedded 
also generate greater receptivity to products of foreign origin or those perceived as international rather than domestic (Featherstone 1990). All these factors help create a climate more favorable to international brands.

Three major patterns of brand architecture or structurecorporate-dominant, product-dominant, and hybrid or mixed-can be identified. However, there is considerable variation even within a given type of structure depending to a large extent on the firm's history and the diversity of its product lines or product businesses. Companies also vary in the extent to which they have a clearly articulated international brand architecture. Some have established an explicit framework and rules guiding the use of brands in international markets, whereas others such as Akzo Nobel have few or no guidelines regarding international branding.

Corporate-dominant architecture tends to be most common among firms with a relatively limited range of products or product divisions or with a clearly defined target market, such as Shell, Kellogg's, Nike, Benneton, and so forth. Product-dominant architecture, in contrast, is typically found among firms such as Akzo Nobel that have multiple national or local brands or firms such as $\mathrm{P} \& \mathrm{G}$ that have expanded internationally by leveraging power brands. Most common is a hybrid or mixed structure, which consists of a mix of global corporate, regional, and national product-level brands or different structures for different product divisions.

These structures are continually evolving in response to the changing configuration of markets or as a result of the firm's expansion strategy in international markets. Both corporate- and product-dominant structures are evolving toward hybrid structures, often adding or combining levels of branding. Firms with corporate-dominant structures are adding brands at other levels-for example, the house or product level-to differentiate between different product divisions or product lines. Productdominant structures, in contrast, especially those that emphasize multiple local (national) brands, are moving toward greater integration across markets by adding corporate or product business-level branding to local products.

Increasingly, firms are establishing an explicit international brand architecture to guide this evolution and facilitate improved cohesion of branding strategy across international markets. This architecture consists of three principal components (see Figure 2): the level in the organization at which a brand is used (i.e., corporate, product business or division, and product or product variant), the geographic scope of a brand (i.e., global, regional, or national), and product scope (i.e., the range of products or product lines on which a brand can be used). The architecture may also specify the extent to 


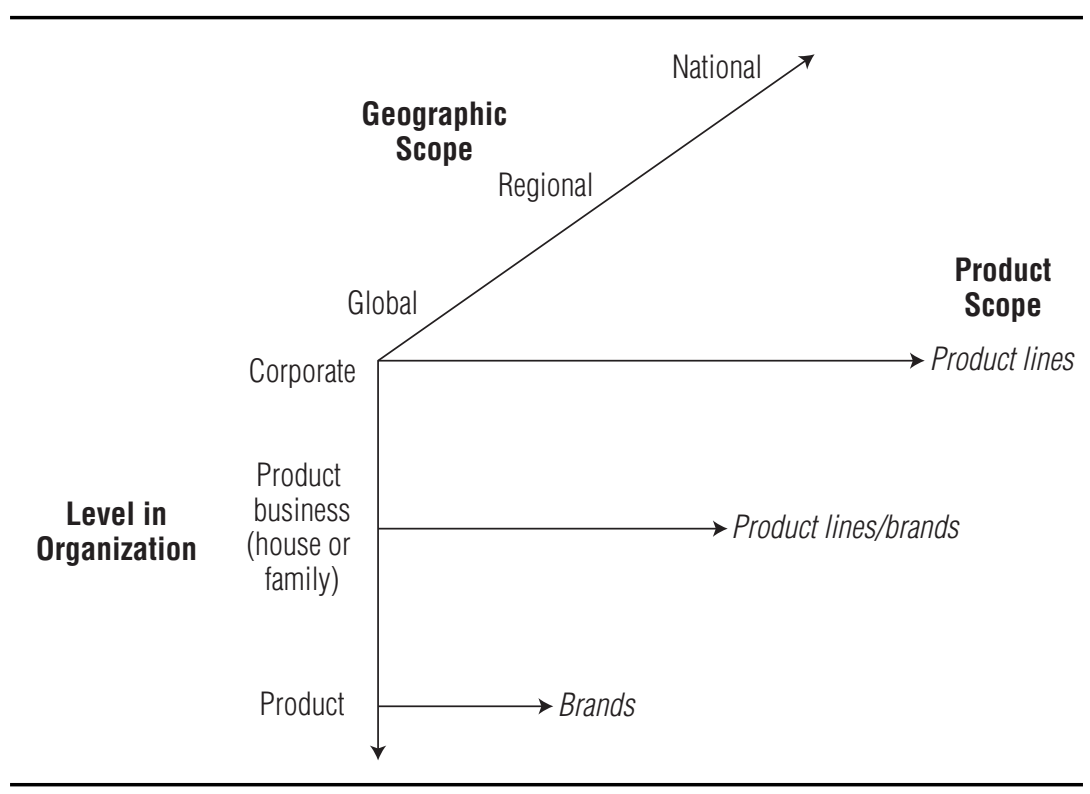

which corporate or product division brands are used to endorse product-level brands. Nestlé, for example, has established an architecture that consists of four levels. This consists of ten worldwide corporate brands, such as Nestlé, Carnation, and Buitoni; 45 worldwide strategic product brands, such as Kit Kat, Polo, and After Eight (these are always endorsed by a corporate-level brand); 25 regional corporate brands; 100 regional product brands, such as Contadina and Stouffer; 700 local strategic brands; and approximately 7000 local brands (Parsons 1996).

At the same time, rising media and promotional costs and the globalization of product-markets create pressures at both the corporate and product level for greater parsimony in branding strategy. As a result, international brand architectures are becoming increasingly characterized by not only corporate endorsement of product brands but also extension of strong brands across countries and product businesses.

Corporate Endorsement. At one end of the spectrum, international expansion and consumer needs for reassurance about product quality and reliability are resulting in a shift toward corporate endorsement of product brands. This helps forge a global corporate identity for the firm and gathers its products under a global umbrella, which generates potential cost savings through promotion of the global corporate brand rather than multiple independent product brands. At the same time, endorsement by the corporate brand provides reassurance for the customer of a reliable corporate image and enhances visibility.

Corporate endorsement of product-level brands is increasingly used as a mechanism to integrate brand structure across
Figure 2.

Dimensions of International

Brand Architecture

\section{Dynamics of International Brand Architecture}


country-markets, providing a unifying element across product offerings. For example, Cadbury uses the Cadbury name on all its confectionery products, in conjunction with product brands such as Dairy Milk, Whispers, and so forth. Equally, a house brand sometimes is used on a product business worldwide. For example, Akzo Nobel places the Sikkens name on all its paint products. The prominence and role of the corporate brand or logo may vary from country to country. For example, Douwe Egbert uses the Friesen lady logo on its coffee in all countries, but the size of the lady and the positioning statement vary from country to country. In Spain, for example, the positioning emphasizes the richness of the coffee and the master brewer, in the United Kingdom the coffee's continental taste, and in Holland the association with family and comfort.

Brand Extension. At the other end of the spectrum, media costs, coupled with the importance of building high visibility and the need to obtain cost economies, create pressures to extend strong brands across product lines and country borders. Increasingly, new products and variants are launched under existing brand names to take advantage of their strength and consumer awareness. Mars, for example, has launched an ice cream line as well as a soft drink under the Mars brand name. Cadbury's Milk Tray brand has been extended to desserts, leveraging the brand's association with creaminess. Strong international brands often have high visibility and are prime candidates for brand extensions, especially for entry into new and emerging markets such as Eastern Europe or China. In some cases, a well-known brand name is used on a product line that is marketed under another brand name elsewhere. For example, Danone uses the Danone name to market bottled water in the United States in order to leverage customer familiarity with the name. Similarly, Nestlé's Maggi brand, used on sauces and seasonings, had high recognition in Eastern Europe and so was extended to frozen foods rather than the Findus brand used elsewhere in Europe.

MANAGERIAL IMPLICATIONS

International markets continue to change rapidly (Craig and Douglas 1996). As markets evolve, firms need to establish an explicit international brand architecture and search for opportunities to reduce the number of brands and improve efficiency as well as harmonize brand strategy across product lines and country-markets. Unilever, for example, has plans to focus on 400 of its 1600 brands. Within these there will be a core group of global and regional power brands (Beck 1999). Focusing on a limited number of strategic brands enables the firm to consolidate its position in international markets and enhance brand power. Effective management of international brand architecture and establishment of procedures to manage and monitor key strategic brands are, however, crucial to maintaining the firm's position and strengthening key strategic brands in international markets. 
Management needs to design an efficient, harmonious brand architecture that spans operations in different countries and product lines. This establishes the framework for decisions related to the firm's brands in international markets. It should clearly define the importance and role of each level of branding, as, for example, at the corporate, product division, or product brand level, as well as the interrelation or overlap of branding at each level. It should also determine the appropriate geographic scope for each level relative to the firm's current organizational structure. The design of this architecture should satisfy three key principles: parsimony, consistency, and endorsement.

Parsimony. The brand architecture should incorporate all the firm's existing brands, whether developed internally or acquired. It should provide a framework for consolidation to reduce the number of brands and strengthen the role of individual brands. Brands that are acquired need to be melded into the existing structure, especially when these brands occupy similar market positions to those of existing brands. Equally, when the same or similar products are sold under different brand names or have different positionings in each country, ways to harmonize these should be examined.

Consistency. Another important element of brand architecture is its consistency relative to the number and diversity of products and product lines within the company. A balance needs to be struck between the extent to which brand names differentiate product lines or establish a common identity across different products. Development of strong and distinctive brand images for different product lines helps establish their separate identities and minimize the risk of negative associations (e.g., between food and chemicals). Conversely, use of a common brand name consolidates effort and can produce synergies.

Endorsement. The value of corporate brand endorsement across different products and product lines and at lower levels of the brand hierarchy also needs to be assessed. The use of corporate brand endorsement as either a name identifier or logo identifies the product with the company and provides reassurance for the customer. In international markets, corporate brand endorsement acts as an integrative force unifying different brand identities across national boundaries. At the same time, corporate endorsement of a highly diverse range of product lines can result in dilution of image. Equally, negative effects or associations can do harm and have long-lasting effects across multiple product lines. Thus, both aspects need to be weighed in determining the role of corporate brand endorsement in brand architecture.

The growing prevalence of corporate endorsement and brand extensions, coupled with a focus on building a limited num-

\section{Designing International} Brand Architecture
Assigning Custody for Key Strategic Brands 
ber of strong brands in international markets, makes it increasingly imperative for firms to develop procedures to manage and monitor key strategic brands. The pivotal role of these brands in global markets implies that it is critical for management to set up procedures to monitor brands to ensure that they retain their integrity, visibility, and value. This entails assigning custody for the brand and establishing procedures for sanctioning brand extensions and monitoring brand positioning.

In arriving at an appropriate custody model, the consistency of brand positioning across different countries (and across product lines), the strength of the local country management, and the desired degree of centralized control need to be considered. Widely different approaches can be adopted for assigning custody and managing strategic brands in international markets, ranging from negotiated solutions to centralized custody at corporate or product division headquarters.

Negotiated Custody. One option is to negotiate the harmonization of specific brand positionings between corporate headquarters and country managers. This is most likely to be appropriate for firms with strong country management that operate in product-markets where brands are not important purchase cues or where brands historically have had different positionings tailored to local market characteristics. For example, Unilever is moving toward great consistency in the positioning of its low-fat margarine brand sold as Flora in the United Kingdom and Promise in the United States. However, this approach may be somewhat cumbersome when there are multiple brands to manage.

Brand Champion. A more proactive and increasingly popular solution is to appoint a brand champion. The brand champion should be given responsibility for building and managing the brand worldwide. This should include monitoring the consistency of the brand positioning in international markets, as well as authorizing use of the brand (brand extensions) on other products or other product businesses. The brand champion can be a senior manager at corporate headquarters, a country manager, or a product development group. For example, a lead country or one with major market share for the brand can be given responsibility for custody of the brand. For example, France has custody of the Lipton brand. It is critical that the brand custodian report directly to top management and have clear authority to sanction and/or refuse brand extensions to other product lines and product businesses so as to maintain the integrity of the brand and avoid brand dilution.

An important issue with brand extensions is to avoid overextension or stretching of the brand and dilution of its equity 
and image. Criteria for sanctioning brand extensions will vary considerably depending largely on the firm's organizational structure, the diversity of its product lines, and its business and management philosophy. In general, however, a proposed extension should be consistent with the core brand's positioning and reinforce or sustain the existing brand concept. For example, extension of a confectionery brand to ice cream or dessert should emphasize the same core attributes. Proposed extensions of strategic brands may also be required to have international market potential.

Centralized Custody. Another model is to centralize control of brands within the global product division. This approach is likely to be most effective with new products or brands when there is greater consistency in market characteristics across countries and a limited history of strong country management. Under centralized custody, brand manuals are often used as mechanisms for ensuring consistency of brand positioning and identification across countries. The brand manual typically is developed at corporate headquarters and details the specific positioning and visual appearance of an international brand packaging, logo, and so forth. Country managers are normally required to stay within these guidelines. Brand manuals, for example, are used by Unilever's ice cream division and Beiersdorf's Nivea brand. ${ }^{2}$

Guidelines for the use of corporate brand identifiers, such as logos, packaging, and so forth, should also be mandated and monitored. Again, the ease with which this can be accomplished will depend on the firm's organizational structure. For example, Nike strictly controls the use of its logo as well as the consistency of its brand positioning and advertising around the world. In general, however, the newer the business and the more it is targeted to a specific global market segment, the more feasible it is that the firm will exercise a high degree of centralized control.

Brand architecture is not a static framework but one that needs to be monitored and modified continually. The mechanisms established for brand custody help ensure that an individual brand is managed in a consistent fashion across multiple countries. However, given the dynamic nature of international markets and the changing competitive realities, the structure must be reviewed at least annually. An international brand architecture audit should be performed to ensure compliance with established procedures and determine whether the structure of the architecture should be changed. This must take place on two levels. First, the degree to which individual strategic brands have adhered to established guidelines must be assessed. Second, the entire portfolio of brands must be examined in terms of whether the overall brand architecture requires modification.

\section{Auditing Brand Architecture}


Compliance Audit. A bottoms-up audit of the individual brands allows an assessment of how well each functions as part of the overall brand architecture of the firm. The key steps of this phase are (1) collection of information that establishes how the brand has been used in each country in which it is marketed, (2) assessment of deviations from the brand's established position in the structure and the reasons for the deviation, and (3) evaluation of the brand's performance. Deviations are particularly diagnostic. They may suggest poor management of the brand globally or, more important, fundamental changes in the underlying market dynamics. If the underlying market dynamics or product-market structure has changed, the brand's position in the overall architecture must be modified accordingly. After these preliminaries are conducted, the audit should culminate in a face-to-face meeting of key participants, including the brand custodian, to establish guidelines for the coming year.

Strategic Audit. The next phase is a strategic, top-down audit, conducted on multiple levels. Logical groupings of strategic brands must be assessed in terms of their compliance with established guidelines. When this has been accomplished, senior management must evaluate the overall structure of international brand architecture to determine the fit at different levels across multiple countries. Again, a key factor here is how the underlying drivers of brand architecture have changed. In addition to market dynamics and the productmarket structure, an important consideration is how the firm itself has evolved, particularly with respect to acquisitions or market expansion initiatives. If the end result of the strategic audit is that the firm's brand architecture no longer fits underlying drivers, steps should be taken to revise the firm's architecture so that it reflects the new realities of the marketplace.

\section{ConCLUSION}

The central role of branding in establishing the firm's identity and building its position in the global marketplace among customers, retailers, and other market participants makes it increasingly imperative for firms to establish a clearcut international branding strategy. A key element of success is the framing of a harmonious and consistent brand architecture across countries and product lines, which defines the number of levels and brands at each level. Of particular importance is the relative emphasis placed on corporate brands as opposed to product-level brands and the degree of integration across markets.

Escalating media costs, increasing communication and linkages across markets, and the internationalization of retailing create pressures for parsimony in the number of the firm's brands and the consolidation of architecture across countrymarkets. Focus on a limited number of international strategic brands generates cost economies and potential synergies 
for the firm's efforts in international markets. At the same time, procedures for managing the custody of these brands must be established. These should be clearly understood and shared throughout all levels of the organization, which leads to a culture and/or mentality that promotes the growth of strong international brands without diluting their strength by overuse or inconsistencies.

1. We conducted a field study of consumer goods companies based in Europe to gain some insights into international brand structures, the way these were evolving, and the underlying drivers of brand structure. Of particular interest was whether the firm had an explicit international brand architecture and, if so, how this was managed. The study was based on semistructured interviews that were conducted with senior executives at the product division level in companies, as well as executives in advertising agencies, market research companies, and consulting companies who were responsible for international brands and branding strategies.

2. Aaker and Joachimsthaler (1999) also suggest establishing business management teams or a global brand manager as means of managing global brands effectively.

Aaker, David (1996), Building Strong Brands. New York: The Free Press.

and Erich Joachimsthaler (1999), "The Lure of Global Branding," Harvard Business Review, 77 (November/December), 137-44.

— and Kevin Keller (1990), "Consumer Evaluations of Brand Extensions," Journal of Marketing, 54 (1), 27-33.

Alden, Dana L., Jan-Benedict E.M. Steenkamp, and Rajeev Batra (1999), "Brand Positioning Through Advertising in Asia, North America, and Europe: The Role of Global Consumer Culture," Journal of Marketing, 63 (January), 75-87.

Bartlett, Christopher A. and Sumantra Ghoshal (1989), Managing Across Borders. Boston: Harvard Business School Press.

Barwise, Patrick and Thomas Robertson (1992), "Brand Portfolios," European Management Journal, 10 (September), 277-85.

Beck, Ernest (1999), "Unilever to Cut More Than 1,000 Brands," The Wall Street Journal, (September 22), A17.

Caller, Linda, ed. (1996), Researching Brands. Amsterdam: ESOMAR.

Court, David C., Anthony Freeling, Mark C. Lerter, and Andrew J. Parsons (1997), "If Nike Can 'Just Do It' Why Can’t We?" McKinsey Quarterly, (3), 25-34.

Craig, C. Samuel and Susan P. Douglas (1996), "Responding to the Challenges of Global Markets: Change, Complexity, Competition and Conscience," Columbia Journal of World Business, 31 (Winter), 6-18.

de Mooij, Marieke (1997), Global Marketing and Advertising, Understanding Cultural Paradoxes. Thousand Oaks, CA: Sage Publications.
NoTES

\section{REFERENCES}




\section{The Authors}

Susan P. Douglas is Professor of Marketing and International

Business, and C. Samuel Craig is Professor of Marketing, Stern School of Business,

New York University.

Edwin J. Nijssen is Professor of Marketing, Nijmegen Business School.

\section{ACKNOWLEDGMENT}

The authors acknowledge the support provided by the Unilever Foundation to the senior author while she was the Unilever Visiting Professor at Erasmus University in Rotterdam.
Douglas, Susan P. and C. Samuel Craig (1996), "Global Portfolio Planning and Market Interconnectedness," Journal of International Marketing, 4 (1), 93-110.

Echikson, William and Dean Foust (2000) "For Coke, Local Is It," BusinessWeek, (July 3), 122.

Featherstone, Mike (1990), "Global Culture: An Introduction," in Global Culture: Nationalism, Globalization and Modernism, Mike Featherstone, ed. London: Sage Publications, 1-13.

Hassan, Salah S. and Lea Katsanis (1994), "Identification of Global Consumer Segments," Journal of International Consumer Marketing, 3 (2), 24.

Kapferer, Jean-Noel (1997), Strategic Brand Management, 2d ed. London: Kogan Page.

Keller, Kevin (1998), Strategic Brand Management. Engelwood Cliffs, NJ: Prentice Hall.

Laforêt, Sylvie and John Saunders (1994), "Managing Brand Portfolios: How the Leaders Do It," Journal of Advertising Research, 34 (September/October), 64-76.

Olins, W. (1989), Corporate Identity. London: Thames and Hudson.

Parsons, Andrew (1996), "Nestlé: The Visions of Local Managers," McKinsey Quarterly, (2), 5-29.

Schmitt, Bernd H. and Alex Simenson (1997), Marketing Aesthetics: The Strategic Management of Brands, Identity and Image. New York: The Free Press. 